\title{
ARTIGOS
}

dx.doi.org/10.11606/issn.25253123.gis. 2020.171664

ORCID orcid.org/0000-0002-0483-5385

\section{FILMES COMO COISAS NA IINDIA COLONIAL}

\section{MARCUS BANKS}

Oxford University, Inglaterra, Reino Unido, OX2 6PE

information@anthro.ox.ac.uk

\section{RESUMO}

Este artigo argumenta que um produto visual também é material, no sentido de que objetos visuais (mesmo digitais) podem circular pelos mais variados espaços e, dependendo do contexto, podem adquirir ou expressar propriedades muito diferentes. Este artigo baseia-se em pesquisas conduzidas pelo autor em arquivos de filmes na Índia e no Reino Unido. O objetivo é mostrar que os filmes de não ficção (e a duração das filmagens) filmados por oficiais coloniais britânicos e visitantes da Índia na primeira metade do século XX formam "documentos" visuais que se baseiam em convenções fotográficas e filmes anteriores. Simultaneamente, o cinema de ficção indiano toma forma, com o trabalho pioneiro de DG Phalke. Os cinemas usam os mesmos materiais, possivelmente os mesmos tipos de câmera, porém sem intersectarem-se. 0 artigo conclui que toda a gama de formas de filme do período citado e posterior deve ser considerada para entender as relações visuais entre o povo indiano como sujeito e os colonizadores britânicos.

\section{ABSTRACT}

This paper argues that the visual is also material, in the sense that visual objects (even digital ones) can circulate through a variety of different spaces and, depending on the context, may acquire or express very different properties. This paper draws upon research conducted by the author in film archives in both India and the United Kingdom, aiming to show that non-fiction films (and lengths of film footage) shot by British colonial officials and visitors to India in the first half of the 20th century form visual "documents" that draw upon earlier film and photographic conventions. Concurrently, the nascent Indian fiction 
film gets underway, with the pioneering work of D. G. Phalke. Both cinemas use the same materials - even possibly the same kinds of camera - yet never intersect. This paper concludes that the full range of film

KEYWORDS

Visual anthropology: colonial film; India. is formed in the period, and subsequently, has to be considered so one can understand visual relations between Indian subjects and British colonisers.

\section{INTRODUÇÃO}

Alguns anos atrás, eu e Howard Morphy observamos que a subdisciplina antropologia visual estava dominada pela produção e pelo consumo de filmes etnográficos (Morphy e Banks 1997, 4 e 5). Nós argumentamos que, enquanto a produção de representações visuais em movimento tematizando a vida cultural e social era, sem dúvida, importante, havia o perigo de que o mainstream, os antropólogos não visuais, cada vez mais deixassem de ver nesses empreendimentos alguma relevância para o seu trabalho. Além disso, como Jay Ruby (2000, 3, 35 e 36, passim) argumentou posteriormente, a produção dos chamados filmes etnográficos se tornou gradualmente dominada por cineastas profissionais que, apesar de produzirem filmes interessantes, desconhecem ou são desinteressados em análises antropológicas.

O artigo provocou uma série de respostas negativas, com a maioria argumentando que Morphy e eu estávamos mais preocupados em policiar as fronteiras disciplinares e subdisciplinares do que promover uma agenda intelectual genuinamente aberta (por exemplo, Taylor 1998). No entanto, poucos fizeram alguma consideração séria sobre o outro ponto central de nosso argumento, ou seja, de que o visual é também material. Isso modifica não apenas o foco principal da subdisciplina - da produção de filmes para o estudo dos objetos -, mas desloca o centro intelectual para longe das temáticas sobre representação e em direção ao estudo das relações sociais. Isso, em nossa opinião, contribui para o aumento, e não diminuição, de abordagens antropológicas e sociológicas. As mídias visuais (ou seja, o filme e a fotografia, mas também o desenho, a pintura e o gráfico) muitas vezes representam objetos e aspectos do mundo material, mas as próprias mídias visuais existem como objetos materiais. Enquanto objetos, circulam pelo mundo dos humanos através dos sistemas de trocas e, consequentemente, se constituem como o principal meio de análise das relações sociais de troca. Isso de nenhuma forma diminui suas qualidades representacionais, pois normalmente são elas que, em primeiro lugar, aparentemente motivam o processo de troca (por exemplo, crianças trocando cigarette 
cards ${ }^{1}$ ["cartas"] de jogadores de beisebol e futebol americano no passado, e atualmente de super-heróis ou Pokémon). De fato, a materialidade das mídias visuais é muitas vezes negligenciada ou analiticamente não notada, mas ignorá-la, em todos os casos, é cometer um grave erro sociológico. Em outras palavras, as mídias visuais não apenas oferecem evidências sobre o mundo material, mas também produzem vestígios sobre si mesmas enquanto objetos no mundo.

\section{EVIDÊNCIA MATERIAL}

É em sua forma representacional que as imagens, na maioria das vezes, são consideradas como evidência. As fotografias do século XIX exibidas em 2001 na mostra da National Portrait Gallery intitulada "The Beautiful and the Damned" ["O Belo e o Maldito"] foram originalmente produzidas para serem evidências da loucura, criminalidade e celebridade social de seus sujeitos (Hamilton e Hargreaves 2001); um século depois, uma imagem granulada de câmera de segurança de um shopping center é chamada de "evidência assustadora da facilidade com que um crime [o sequestro e, consequentemente, o assassinato de uma criança] foi cometido e posteriormente desvendado" (Mirzoeff 1999, 2); David Hemmings, fotógrafo no filme Blowup (1966), de Antonioni, acidentalmente fotografa o que parece ser um assassinato em um parque de Londres. Contudo, em nenhum desses casos as imagens são realmente evidência do que é alegado. Bertillon, Huxley e outros fotógrafos "científicos" do século XIX estavam trabalhando com uma agenda falha, que falsamente presumia uma correlação entre a fisionomia e a patologia social ou médica: uma conexão que poderia ser confirmada e mapeada através da câmera. ${ }^{2}$ As imagens em vídeo do shopping center, embora, sem dúvida, tenham sido consideradas como evidência no processo judicial, apenas atuam enquanto força probatória como parte de uma cadeia de evidências: não há nenhum "indício" nas imagens de que o crime foi cometido. E a condução da narrativa em Blowup gira, é claro, em torno da ambiguidade presente nas imagens, que atua por si só como uma metáfora da ambiguidade envolvendo o status, as motivações e o estado mental do personagem Hemmings. Em síntese, a evidência representacional é complexa, cheia de camadas e sujeita a interpretação em cada etapa.

Evidências materiais são igualmente complexas, ainda que se originem do irredutível e simples fato de sua presença material. Como observou

\footnotetext{
1. N.T.: Escolhi manter o termo original por não encontrar uma tradução que contemple seu sentido na língua inglesa. Uma breve pesquisa mostra que no Brasil não houve a prática de circular imagens de esportistas em maços de cigarro, como era comum em países como Estados Unidos e Inglaterra. No Brasil, durante os anos 1970, existiram as cartas de jogadores de futebol ("futebol cards"), que eram comercializadas por uma marca de goma de mascar chamada PingPong.

2. No entanto, o desenvolvimento da foto de ficha policial ["mug shot"], perfil e frontal, de Bertillon para a identificação de criminosos ainda permanece em uso nos dias de hoje; ver também Phillips, Haworth-Booth e Squiers (1997).
} 
Christopher Pinney (1992), enquanto os modos realistas de representação visual dominantes no Ocidente dependem de uma unidade entre tempo e espaço e presumem uma única forma de visualizar os assuntos, isso não é universal (Pinney argumenta sobre a Índia enquanto uma exceção) nem determinado pela representação fotomecânica. 0 que, entretanto, une as práticas representacionais fotográficas da Índia e do Ocidente é a ocupação de pontos fixos no espaço-tempo pelos objetos materiais da representação. Enquanto as coisas representadas podem ser únicas ou múltiplas, e o modo de representação pode ser linear e perspectivo ou fragmentado e montado, os objetos que carregam essa representação - tiras de filme, fotografias, pôsteres - são únicos, singulares e localizáveis, no tempo, se não também no espaço. Do mesmo modo, e indo além da materialidade das próprias imagens-objeto, as condições materiais para que algumas delas existam, e sejam preservadas e reproduzidas ${ }^{3}$, são moduladas por condições sociais e econômicas locais (por exemplo, relações de mercado do capitalismo tardio), mas apenas até certo ponto: banhos de revelação química e a litografia offset provavelmente funcionam da mesma forma enquanto processos técnicos na Índia e no Ocidente, independentemente das relações sociais que permeiam esses processos. Por fim, graças às semelhanças de existência e origem, as imagens-objeto muitas vezes devem, se não sempre, ser consideradas em diálogo com outras imagens-objeto, assim como com seus produtores, proprietários e consumidores; independentemente da evidência oferecida pelas imagens-objeto, elas agem de forma contingente e dentro de um campo de relações sociais que as influenciam e por elas são influenciadas. Todos os objetos estão envolvidos em relações sociais por aqueles que os possuem, trocam e almejam controlá-los (para exemplos de histórias coloniais do Pacífico, ver Thomas 1991), e todas as imagens-objeto se originam de sua capacidade de construir sentido através de relações com o outro (ver Edwards 2001, capítulo 2, para exemplos de arquivos). Em outra ocasião eu já abordei as práticas ocidentais contemporâneas de troca, circulação e mercantilização de imagens-objeto (Banks e Zeitlyn 2015, 57 a 61, 66 a 70), mas eu gostaria de seguir o exemplo proposto por Thomas (2001) e Edwards (2001) e considerar a circulação de imagens-objeto em um contexto colonial de dominação e resistência à dominação: o fluxo de filmes enquanto objetos na Índia no final do período colonial.

Os filmes indianos do período colonial - tanto aqueles produzidos por britânicos residentes ou visitantes quanto aqueles produzidos pelos

3. Enquanto a relação entre uma fotografia "original" e suas posteriores reproduções pode ser uma questão interessante (Banks 2001, 60, Benjamin 1992), para os objetivos deste argumento todas as reproduções são únicas em sua materialidade. A "mesma" imagem pode ser reproduzida em milhares ou milhões de cópias - em um jornal diário, por exemplo -; entretanto, em cada caso a "performance" dessa imagem (Edwards 2001) é ligeiramente diferente, dependendo do contexto histórico e social de seu consumo. 
próprios indianos - sem dúvida podem ser "lidos" apenas pelos seus conteúdos superficiais. O estudioso indiano Ashish Rajadhyaksha (1994), por exemplo, concluiu através de uma leitura dos primeiros filmes comerciais indianos que o espaço "privado" da casa, personificado nos papéis das esposas e mães nas narrativas ficcionais, representou um lugar específico do nacionalismo anticolonial, enquanto meu próprio entendimento a respeito dos filmes amadores britânicos da Índia no mesmo período revela, em contraponto, uma fascinação pelas mulheres indianas veladas e misteriosas nos espaços "públicos" das ruas e dos campos. Da mesma forma, muitos dos primeiros filmes comerciais indianos não demonstravam nenhum interesse particular pelos papéis femininos e pelo espaço doméstico, enquanto vários filmes amadores britânicos estavam mais interessados nas atividades sociais das mulheres britânicas de classe alta em festas de jardim e recepções de governadores do que em tentar entender o que havia por trás do véu de suas congêneres indianas de classe baixa. É necessário, portanto, ampliar a perspectiva de abordagem, ao menos inicialmente, para considerar o grande espectro de filmes em circulação durante a última década de dominação colonial. Também é necessário considerar os filmes como objetos, não tanto no sentido literal, como rolos de celuloide, mas como a síntese e a incorporação de uma série de processos sociais e materiais.

\section{UMA BREVE TIPOLOGIA DO FILME NA PAISAGEM MIDIÁTICA [MEDIASCAPE] COLONIAL INDIANA4}

Foi em julho de 1896 que a primeira imagem cinematográfica foi vista na Índia, em uma exibição de curtas-metragens dos irmãos Lumière no Hotel Watson, em Bombaim, apenas alguns meses depois de terem sido exibidos pela primeira vez na Europa. As exibições atraíam e eram destinadas a uma plateia de europeus - ou seja, britânicos -; porém, passados dois anos, os próprios indianos começaram a experimentar a tecnologia. Assim como na Europa e na América, após as experiências preliminares, o filme se estabeleceu depressa na Índia, expandindo-se rapidamente por todo o subcontinente.

As histórias tradicionais do cinema indiano dão ênfase exclusivamente ao desenvolvimento da indústria cinematográfica local de longas-metragens indianos, muitas vezes procurando evidenciar conexões e continuidades estilísticas com as espetaculares formas antigas e pré-cinematográficas,

\footnotetext{
4. Por necessidade, o exame a seguir deve se manter breve, possivelmente muito curto, e os detalhes estão de qualquer maneira submetidos aos propósitos de minha argumentação geral neste artigo. Espero, em momento oportuno, publicar mais sobre os filmes discutidos em sua própria essência e em seu contexto histórico adequado. Salvo indicação em contrário, o material a seguir é baseado em artigos das obras de Chabria e Cherchi Usai (1994), Rajadhyaksha e Willemen (1994), e em minha própria pesquisa de arquivo no Indian National Film and Television Archive (Pune), no Maharashtra State Archives (Mumbai) e no Centre for South Asian Studies (Cambridge).
} 
como o teatro de sombras [shadow puppetry] e pinturas de narrativas religiosas. Mas os dramas mitológicos, muito associados ao desenvolvimento do cinema indiano, não eram a única forma fílmica encontrada: um exame ampliado da "paisagem cinematográfica" ["cinemascape"] (para emprestar e adaptar uma noção de Arjun Appadurai) revela que havia ao menos quatro tipos distintos de filmes-objeto em circulação durante as primeiras quatro décadas do século XX:

(1) Os primeiros filmes a serem comercialmente exibidos na Índia - assistidos por indianos assim como por europeus - eram todos importados da Inglaterra e dos Estados Unidos. Esses filmes importados foram dominantes até o final da década de 1920, quando o Comitê Cinematográfico Indiano, patrocinado pela Grã-Bretanha, recomendou que a indústria de filmes local deveria ser incentivada a fim de produzir mais filmes para o mercado interno. Esses primeiros filmes importados eram uma mistura de clássicos familiares (para nós, nos dias de hoje), como Desert song [A canção do deserto] (1929) e Broadway melody [Melodia da Broadway] (1929), assim como picantes filmes "B" americanos, como Party girl [Garotas perigosas] (1930) e Convention city [Que semana!] (1933) (não assisti a nenhum dos dois, mas ambos tiveram os certificados de exibição proibidos devido a seus "baixos princípios morais").

(2) Uma indústria local, entretanto, iniciou-se antes. O primeiro filme comercial geralmente reconhecido é Raja Harishchandra (1913), produzido em Bombaim por D. G. Phalke (inspirado em um episódio do épico hindu Mahabharata); posteriormente, durante as duas décadas seguintes, cerca de 1.300 filmes foram produzidos. A maior parte das produções era criada a partir do que logo ficou conhecido como "mitológicas" - ou seja, dramatizações de histórias do Ramayana, do Mahabharata e de outros textos épicos e religiosos hindus. De modo geral, a vida na Índia durante aquele período - filmada de modo realista ou não - não era tema do cinema comercial indiano inicial.

(3) Mas havia muita atividade cinematográfica em outros lugares da paisagem visual indiana, mesmo que em escala diferente do cinema comercial. Na década de 1920, organizações não governamentais importavam e exibiam regularmente filmes documentais para as plateias indianas com objetivos educacionais. Em 1926, por exemplo, o British Social Hygiene Council [Conselho Britânico de Higiene Social] propôs ao governo de Bombaim exibir vários filmes sobre doenças venéreas para estudantes indianos de medicina. ${ }^{5}$ Na década de 1930, documentários

5. Assim como três filmes informativos sobre Sífilis, Gonorreia e Doenças venéreas nos homens, eles também desejavam exibir dois filmes dramatizados: The shadow ("uma expressiva apresentação dos males relacionados ao tratamento de curandeiros, aliada a uma narrativa comovente") e Tudo que o homem semeia [Whatsoever a man soweth] ("uma história de dois irmãos que ingressam no exército mostra os efeitos desastrosos 
educacionais estavam em processo de produção por essas organizações na Índia, e eventos anuais, como a semana "Bebê e Saúde", da presidência de Bombaim, e a semana da "Cruz Vermelha", exibiam tanto filmes importados quanto produções locais, como Relentless foe (sobre tuberculose) e Slaves of custom (sobre os males dos casamentos precoces).

(4) Fora da esfera comercial e educacional há uma última categoria de filmes-objeto: são os filmes produzidos localmente por cineastas amadores britânicos e que tiveram uma circulação bastante restrita. Até agora consegui rastrear por volta de cem filmes não comerciais realizados por britânicos residentes ou visitantes na Índia durante o período anterior à independência, embora deva haver muitos mais. Desconsiderando alguns registros de viagem feitos por empresas comerciais, a produção de filmes amadores se inicia no fim dos anos 1920, sendo a maior parte deles realizada nos anos 1930. Eles tratam de temas diversos, como métodos de irrigação agrícola, esqui nas férias, viagens de trem, vida doméstica e a herança arquitetônica indiana - 0 Taj Mahal, o Forte Vermelho, e assim por diante. ${ }^{6}$ Por fim, há algumas categorias fílmicas menores: filmes de propaganda missionária, noticiários estrangeiros e os chamados filmes "Reais", encomendados pelos governantes dos estados indianos independentes. No final do período colonial, ocorre uma última investida visual britânica na Índia através do documentário griersoniano: com o objetivo de educar, informar e construir um tipo particular de caráter nacional, já que estava em curso a Segunda Guerra Mundial.

Contudo, uma mera tipologia de formas fílmicas não traz um amplo entendimento dos espaços discursivos abertos e deslocados de forma a permitir um diálogo visual entre os britânicos e os indianos. Para fazer isso, precisamos considerar as trajetórias dos filmes como objetos, como representantes de uma classe de objetos (bens comuns em sua fase de mercadoria, seguindo Igor Kopytoff - por exemplo, as várias cópias comerciais dos filmes de ficção em circulação) e como objetos singulares - únicos e imutáveis (por exemplo, as cópias únicas de muitos filmes amadores) (Kopytoff 1986, 69).

na vida daquele que sucumbe às tentações e a próspera carreira do outro que se mantém no caminho") (Home Political Department, 1926-27, Pasta 171, Governo de Bombaim, Maharashtra State Archive, Mumbai). Tudo que o homem semeia, pela descrição, parece ser bastante similar ao filme da Cruz Vermelha da África do Sul nos tempos de guerra, Sr. Sensato e Sr. Insensato [Mr. Wise and Mr. Foolish], ele mesmo uma versão de outro filme (Vaughan 1991, capítulo 8), demonstrando que alguns espaços de circulação visual eram tão grandes como o próprio Império.

6. Esses filmes formam uma classe em virtude de sua produção e de seu (presumido) consumo, e não por sua forma, estilo, assunto ou qualquer outra qualidade representacional. 


\section{OS ESPAÇOS DE VER E SER VISTO}

A grande era da interação visual entre britânicos e indianos aconteceu durante o século XIX, quando cada lado procurou expressar sua compreensão do outro através das mídias visuais - primeiro, através da pintura, gravura e das artes plásticas tridimensionais, e então, a partir da metade do século, através da fotografia. ${ }^{7}$ Naquela época, na Índia, filmes-objeto eram bastante numerosos e estavam suficientemente incorporados à paisagem visual para que adquirissem agência e começassem a circular com trajetórias estáveis através dessa paisagem. Os princípios da investigação visual do século XIX foram perdendo intensidade - os intermináveis projetos fotográficos sobre raças e tipos de pessoas foram reduzidos a quase nada. Em certo sentido, os filmes-objeto indianos, em seu modo representativo, têm pouco a nos contar a respeito do engajamento mútuo entre britânicos e indianos.

FIGURA 1

Dhobi ghat Lahore, 1930. Fonte:

Banks 1, com a gentil permissão do Centre of South Asian Studies da Cambridge University.

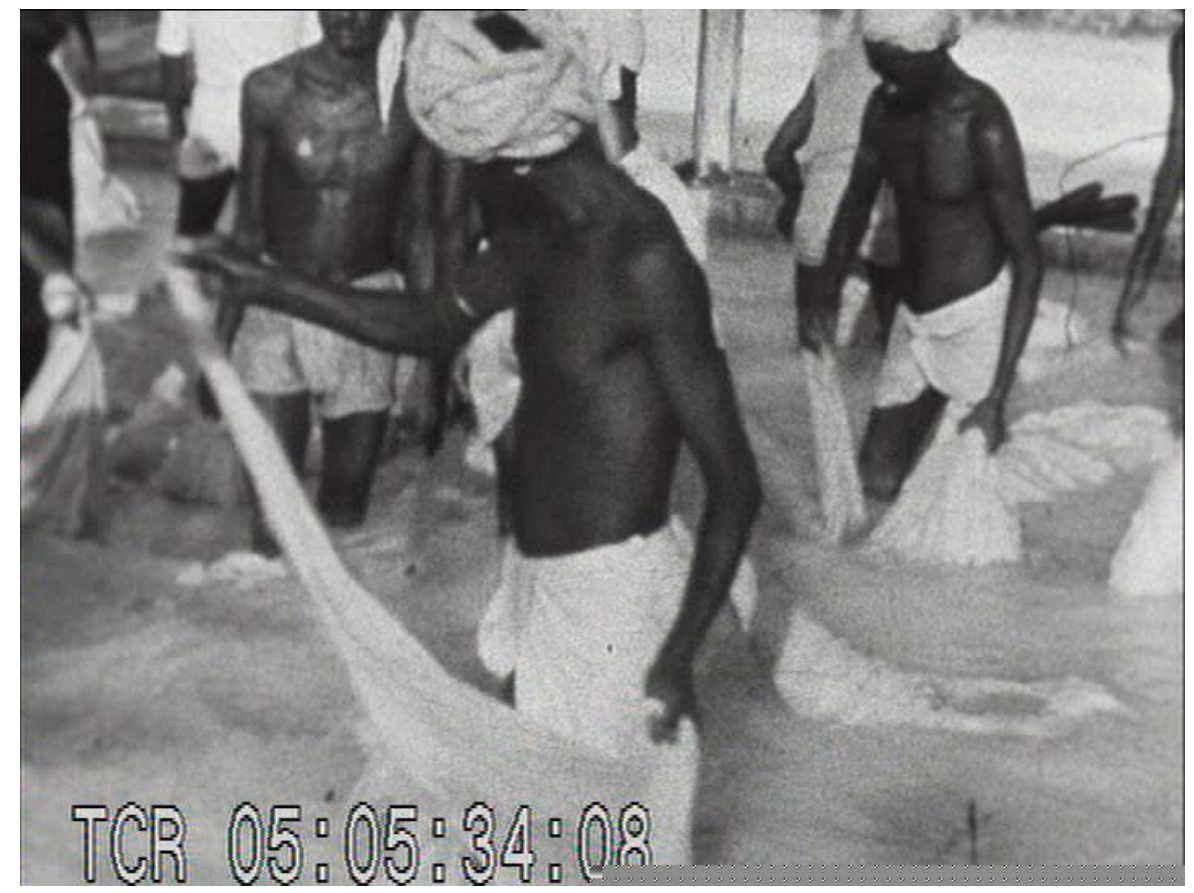

7. Esse olhar fotográfico não era exatamente recíproco, como Christopher Pinney (1997) e outros demonstraram, mas tampouco era unilateral. Enquanto alguns dos fotógrafos britânicos e europeus estavam combinando as novas ciências da fotografia e antropometria em uma tentativa de mapear as raças e os tipos do homem indiano (um projeto complicado pela óbvia e, ainda assim, enlouquecedora e obscura hierarquia social das castas), os indianos procuravam se entender através da fotografia, um projeto complicado, porém possibilitado pelas transformações que a presença britânica trouxe para a compreensão da concepção de si. Por volta da segunda ou terceira década do século XX, estava claro que a simples análise visual dos indianos pelos britânicos - ou vice-versa revelaria pouco sobre suas essências ou seus modos de sociabilidade. 
No entanto, eles não são totalmente mudos. Por exemplo, alguns filmes amadores britânicos ainda mantinham resquícios de "tipos e raças", típicos de alguns projetos fotográficos do século XIX, que no contexto indiano rapidamente se transformaram em uma tipologia de castas e profissões. A Figura 1 mostra a cena de um filme realizado por meu homônimo Dick Banks sobre os dhobis, ou lavadores (washermen), de Lahore. Banks, funcionário das Imperial Chemical Insdustries (ICI), foi enviado à Índia em 1929 para pesquisar um lugar para a instalação de uma nova indústria química e, como muitos outros viajantes, aproveitou a oportunidade para filmar os lugares que viu durante sua viagem. Fotografias de lavadores, assim como de barbeiros, ceramistas, ferreiros e afins, eram imagens de arquivo nas pesquisas fotográficas do século XIX.

Mas, além desses traços, há uma área, um espaço discursivo, pela qual todos os filmes-objeto circularam e exerceram sua agência de forma bastante distinta. A ascensão do cinema na Índia desde o início do século XX corresponde à ascensão de um conjunto de ações e representações coerentes e cada vez mais poderosas em torno da questão da independência indiana, ou "autogoverno" ["home rule"], como era conhecido. Embora seja possível debater o movimento nacionalista indiano em termos abstratos, ou rastreá-lo em artigos e escritos de políticos, a ideia de nacionalismo no sentido de um projeto de vida só é possível através da investigação dos agentes que contribuíram para os debates e mediante a análise das ações e dos objetos a que eles atribuíram um significado nacionalista. Um exemplo dessa classe de objetos - embora não seja necessariamente um dos mais expressivos - são os filmes produzidos na Índia antes da independência. ${ }^{8}$

A leitura convencionada da fotografia indiana - e, portanto, de filmes indianos posteriores - sustenta que a "tradição" estilística e as propriedades formais pré-fotográficas e pré-cinematográficas das formas visuais indianas são mantidas até a era da câmera (e.g. Gutman 1982). Entretanto, tal abordagem negligencia um cenário político extremamente carregado e modificado dentro do qual essas formas visuais tardias circularam (Pinney 1997, 96).

Por exemplo, relata-se que D. G. Phalke, já mencionado anteriormente e conhecido hoje em dia como o "pai do cinema indiano", teria dito, quando assistiu a um filme britânico importado, The life of Christ [A vida de Cristo], no final de 1910 ou início de 1911: "enquanto The life of Christ estava passando rápido diante de meus olhos, eu estava mentalmente visualizando os deuses - Shri Krishna, Shri Ramachandra, sua Gokul e Ayodhya [lugares geográficos de grande significado para a mitologia hindu]... Poderíamos nós, filhos da Índia, ser capazes de ver imagens

8. Possivelmente a classe mais significativa de objetos dotados de significado nacionalista no período são as roupas - ver Bayly (1986) e Tarlo (1996). 
indianas na tela?" (Chabria 1994, 8). De fato, formas estéticas tradicionais podem ter sido empregadas no estilo e na forma subsequente do cinema indiano, mas elas foram estimuladas por uma conjunção de mudanças nas circunstâncias políticas $e$ técnicas, e não simplesmente transferidas, sem problematização, de um suporte para outro. Não foi somente a tecnologia ou a forma fílmica que empolgou Phalke e estimulou a criação de seus filmes, mas as potenciais trajetórias que ele pôde imaginar para posteriormente criar os filmes-objeto: as representações dos deuses e heróis indianos, certamente, mas também objetos que poderiam circular por toda a sociedade indiana como representativos daquele conhecido termo gandhiano: swadeshi - "indústria doméstica" -, um movimento político e social que buscava promover a criação e o uso de produtos feitos em casa - de forma mais contundente, as roupas em detrimento do uso dos produtos britânicos importados. Phalke posteriormente disse: "Meus filmes são swadeshi, pois o capital, a propriedade, os empregos e a história são swadeshi” (Rajadhyaksha 1994, 38).

o espaço em que Phalke e outros pioneiros do cinema comercial indiano procuraram inserir seus filmes-objeto era um campo altamente regulamentado. O Governo (colonial britânico) da Presidência de Bombaim procurou controlar esse espaço de duas formas: primeiro, regulando o conteúdo representacional dos filmes produzidos e distribuídos e, em segundo lugar, regulando os espaços físicos em que os filmes eram exibidos; ou seja, regulando sua materialidade. Nenhuma dessas questões era simples, pois a regulação do conteúdo e do contexto performativo inevitavelmente confinou ou bloqueou os canais percorridos tanto pelos filmes locais como pelos estrangeiros. Por exemplo, no campo da moralidade havia tanta rigidez por parte do Bombay Board of Film Censors [Conselho de Censores Fílmicos de Bombaim] ao perseguir lascívia ou obscenidade nos filmes " $\mathrm{B}$ " americanos importados quanto ao perseguir tais características nos filmes indianos localmente produzidos. No entanto, nessa questão, a representação de nudez parcial (por exemplo) não era tida como ofensiva ou perigosa de forma abstratamente generalizada. A nudez parcial feminina nos filmes americanos era perigosa pela percepção distorcida da mulher branca, o que provocaria no público indiano a perda do respeito pelos britânicos, cujas mulheres deveriam representar a síntese da pura virtude cristã; em contrapartida, qualquer cena de nudez parcial feminina nos filmes indianos meramente inflamaria desejos e levaria, em último caso, a doenças venéreas. Portanto, as distintas biografias e trajetórias dos dois tipos de filme - americanos e indianos -, ao mesmo tempo que os sujeitaram aos mesmos tipos de restrição em sua circulação, também trouxeram um reconhecimento implícito de suas diferenças contextuais enquanto filmes: as relações sociais e as práticas de exibição na América, embora desagradáveis para o Conselho, foram reconhecidas por respaldar um espaço que permitia a existência de certos 
filmes-objeto nos Estados Unidos, mas as distintas relações sociais na Índia não possibilitaram a existência desse mesmo espaço.

Mas era o espaço para o discurso nacionalista que os britânicos buscavam rigorosamente controlar, especialmente após 1927, quando o Comitê Cinematográfico Indiano recomendou que a "solução" para o perigo apresentado pelos filmes “imorais" importados dos Estados Unidos não era substituí-los por produções britânicas moralmente corretas, mas apoiar e estimular a indústria local. ${ }^{9}$ Assim, os cineastas indianos procuraram enviar uma variedade de filmes-objeto para a paisagem midiática indiana [mediascape]. A maioria dos filmes explicitamente políticos - documentários ou sequências reais de agitação nacionalista - eram natimortos, reduzidos a chamas antes mesmo de começarem a circular e acumular valor. Por exemplo, em 1931, P. V. Rao produziu Marthanda Varma, um relato do lendário fundador, no século XVIII, do Estado de Travancore, no sul da Índia, mas o filme nunca foi aprovado para lançamento, pois nele eram encontradas representações de uma insurreição camponesa, introduzidas através de intertítulos como: "Filhos da terra amantes da liberdade. Apertem suas armaduras e lutem pelos seus direitos de nascença. Levantem-se...!". Analogamente, em setembro de 1934, M. B. Bilmoria, um cineasta e fornecedor de equipamentos de Bombaim, escreveu para o secretário do Ministério de Assuntos Internos [Home Department] do governo de Bombaim: "Gostaríamos de produzir um filme sobre a tramitação das reuniões do Congresso que acontecerão em Bombaim no próximo mês, mas, antes de o realizar, gostaríamos de saber se a película poderá ser colocada em exibição na Índia, pois, se não houver nenhuma chance de ser exibida, não gostaríamos de arcar com esses custos por nada". A ele foi dito que, enquanto o filme não fosse realizado, não seria possível decidir sobre sua exibição; como não há nenhuma referência posterior ao filme, provavelmente Bilmoria decidiu não se dar esse trabalho (Home Political Department, 1934, Pasta 178, Governo de Bombaim, Maharashtra State Archive, Mumbai).

Alguns nacionalistas foram, no entanto, eventualmente capazes de inserir sua agência nos filmes-objeto. Por exemplo, no final dos anos 1930, nacionalistas por vezes interviam em cópias de filmes comerciais inofensivos - alterando seus aspectos materiais enquanto objetos e os enviando através de novos percursos - inserindo nelas materiais adicionais. Durante as exibições do aparentemente brando Prem Veer [Amor heroico] no cinema Novelty, em Ahmedabad, capital do estado de Guzerate, em dezembro de 1937, um intertítulo foi inserido, na língua guzerate, convidando o público a se levantar de seus lugares e cantar o hino nacionalista hindu "Vande

9. Os estímulos recomendados incluíam incentivos financeiros para os produtores, a abolição de impostos obrigatórios sobre estoque bruto e a redução dos tributos sobre entretenimento. Enquanto a administração britânica simplesmente ignorou o relatório, ficou óbvio, pelo volume da subsequente produção indiana, que ele ainda assim enviou uma poderosa mensagem aos produtores locais. 
Matram", que estava banido (Home Political Department, 1938, Pasta 49, Governo de Bombaim, Maharashtra State Archive, Mumbai).

No geral, porém, foram os filmes comerciais produzidos na Índia com temas mitológicos que tiveram mais sucesso - tanto com o Board of Censors [Conselho de Censores] quanto com o público -, e apesar de alguns autores posteriores afirmarem que há sentimentos nacionalistas codificados nesses filmes (e.g. Rajadhyaksha 1994), não há nenhuma evidência clara de que o público da época interpretou esses filmes dessa forma. Em contrapartida, os filmes amadores britânicos seguiram trajetórias bem diferentes dos filmes comerciais indianos e dos documentários de propaganda britânicos. Por um lado, como não eram destinados a lançamentos comerciais, estavam isentos de restrições da censura e podiam mostrar coisas antes impensáveis. Por exemplo, no início dos anos 1930, Charles Hunter produziu um filme amador de quatro minutos sobre a produção de algodão e sua tecelagem, dentro do qual, brincando, inseriu um intertítulo em que se lia: "Fiando no 'chakra' do sr. Gandhi ['roda de fiar', mas também um símbolo do nacionalismo indiano ou, ao menos, hindu]"10 referência que poderia ter severamente restringido o movimento de um filmes-objeto indiano em seu percurso no circuito de distribuição comercial. Por outro lado, exatamente porque os filmes amadores britânicos não eram feitos para lançamentos comerciais, sua circulação enquanto objeto era extremamente restrita. Quanto a suas biografias, esses filmes geralmente têm vidas discretas e, em grande parte, desde a sua produção permanecem inéditos em arquivos, porões e sótãos. ${ }^{11} \mathrm{~A}$ ausência de visibilidade desses filmes nas posteriores discussões acadêmicas sobre 0 período final da colonização indiana parece estar relacionada a seu longo retiro nos arquivos e à falta de oportunidade para exibi-los.

\section{CONCLUSÃO: FILMES COMO COISAS}

Tanto longas-metragens comerciais indianos quanto filmes amadores britânicos do mesmo período circularam pela paisagem midiática [mediascape] colonial indiana com trajetórias independentes entre si, mas que esporadicamente se cruzavam. Quanto a seu consumo e sua produção, eles existiram - e continuam a existir - isolados em seus campos de troca ou campos de consumo..$^{12}$ Mas, em termos de relações sociais

10. Caçador 7 "Algodão", Centre of South Asian Studies, Cambridge University.

11. Nos últimos anos, no entanto, suas biografias ganharam novos capítulos. À medida que alguns acadêmicos como eu se interessava por eles, eles se tornavam cada vez mais procurados pelas empresas de produção televisiva, que os levaram, pela primeira vez, a existir enquanto mercadoria (Kopytoff 1986), comprando os direitos de exibição dos arquivos que os detinham para incorporá-los em documentários modernos sobre a Segunda Guerra Mundial, o Império Britânico, as reminiscências coloniais britânicas e assim por diante. 12. Uma exceção foram os filmes britânicos de propaganda, que circulavam nos mesmos espaços que os longas-metragens localmente produzidos, especialmente durante o período em que os documentários griersonianos eram obrigatoriamente exibidos nos cinemas indianos antes dos filmes principais. 
entre seus produtores, temas e consumidores, esses vários filmes-objeto passaram pelos mesmos espaços discursivos e, hoje em dia, ainda mantêm um diálogo uns com os outros.

FIGURA 2

Krishna criança combate a cobrademônio Kaliya.

Fonte: Kalya Mardana (1919), de D. G. Phalke, com a gentil permissão do National Film and Television Archive (Pune).

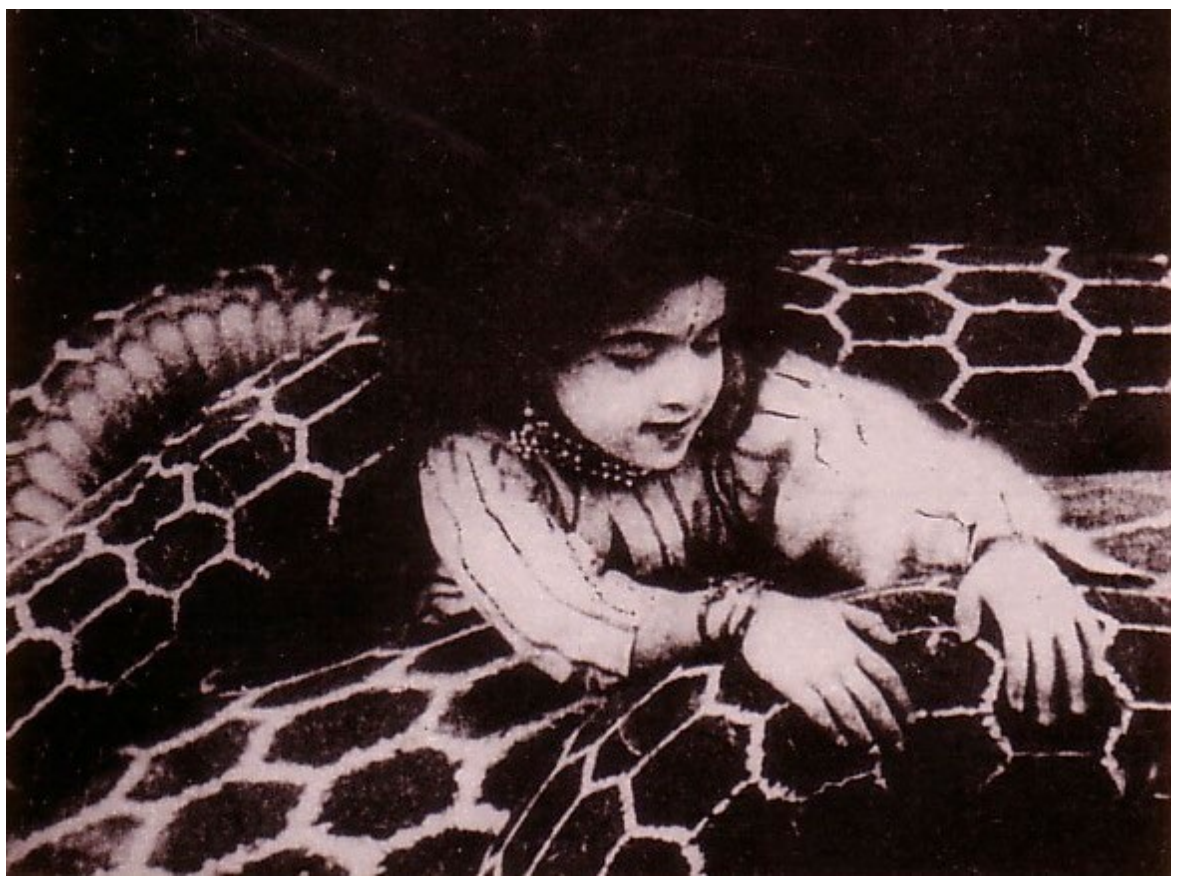

A relevância de entender filmes como objetos, seja circulando como mercadorias ou de outra forma, consiste em compreender os caminhos para a ação e o engajamento social que suas trajetórias performativas abrem. Por exemplo, ao recriar o passado mitológico indiano em seus filmes, Phalke e seus sucessores abriram espaço para abordar uma Índia independente, embora hindu, em que as ações sociais se realizam entre pessoas conhecidas e (mesmo se forem deuses ou demônios) com resultados conhecidos (veja Figura 2) - em nítido contraste de resultados em relação às trajetórias imprevisíveis com que os próprios filmes se depararam, sujeitos que estavam a pressões comerciais e regulamentações britânicas. Por outro lado, os documentários amadores britânicos costumavam se envolver com o presente da Índia, mas um presente localizado em um passado quase etnológico, que não se relacionava com o presente imperial das festas de jardim e recepções dos governadores. Em contraste com um contexto de crescente sentimento nacionalista e agitação política urbana, os amadores britânicos buscavam criar e circular objetos entre seus amigos na Índia colonial e de volta à Grã-Bretanha que contavam uma história de relações agrárias harmoniosas, mas pré-industriais - vindo daí os filmes etnológicos sobre diferentes formas de irrigação. 
TRADUÇÃO

Rafael Franklin Almeida Bezzon

REVISÃO DA TRADUÇÃO

Edgar Teodoro da Cunha

Compreender apenas o conteúdo narrativo de filmes indianos mitológicos comerciais, ou só de documentários amadores britânicos, ou só de filmes profissionais de propaganda, nos conta algo, mas não muito, sobre as relações visuais na Índia colonial. Os documentários amadores britânicos, apesar de aparentarem a transparência de um registro narrativo de eventos, são relativamente mudos enquanto tema de interesse sociológico. Eles realmente só podem ser entendidos e fazer sentido para nós, atualmente, quando compreendidos como objetos em circulação, estabelecidos em seu contexto social e visual, no qual se incluem os dramas mitológicos de Phalke e filmes da Cruz Vermelha sobre os melhores cuidados com bebês. Compreender esses filmes como membros distintos de uma única classe de objetos, sujeitos a restrições diferenciadas em sua circulação e seus contextos de performance, nos permite entendê-los como parte de uma conversa visual entre todos os criadores e consumidores do período. As biografias dos filmes-objeto do período colonial revelam o hoje não individualmente, mas coletivamente, ao passo que revelam uma rede de trajetórias de ações sociais pelas quais britânicos e indianos poderiam transitar.

\section{REFERÊNCIAS BIBLIOGRÁFICAS}

Banks, Marcus and David Zeitlyn. 2015. Visual methods in social research. London: Sage.

Bayly, Christopher A. 1986. The origins of swadeshi (home industry): cloth and Indian society: 1700-1930. In The social life of things: commodities in cultural perspective, ed. Arjun Appadurai, 285-322. Cambridge: Cambridge University Press.

Benjamin, Walter. 1992. The work of art in the age of mechanical reproduction. In Illuminations, ed. Hannah Arendt, 211-244. London: Fontana.

Chabria, Suresh. 1994. Before our eyes: a short history of India's silent cinema. In Light of Asia: Indian silent cinema 1912-1934, eds. Suresh Chabria and Paolo Cherchi Usai, 3-24. New Delhi: Wiley Eastern.

Chabria, Suresh and Paolo Cherchi Usai, eds. 1994. Light of Asia: Indian silent cinema 19121934. New Delhi: Wiley Eastern.

Edwards, Elizabeth. 2001. Raw histories: photographs, anthropology and museums. Oxford: Berg.

Gutman, Judith. 1982. Through Indian eyes: 19th and early 20th century photography from India. New York: Oxford University Press.

Hamilton, Peter and Roger Hargreaves. 2001. The beautiful and the dammed: nineteenthcentury portrait photography. London: National Portrait Gallery.

Kopytoff, Igor. 1986. The cultural biography of things: commoditization as process. In The social life of things: commodities in cultural perspective, ed. Arjun Appadurai, 64-92. Cambridge: Cambridge University Press.

Mirzoeff, Nicholas. 1999. An introduction to visual culture. London: Routledge.

Morphy, Howard and Marcus Banks. 1997. Introduction: rethinking visual anthropology. In Rethinking visual anthropology, eds. Marcus Banks and Howard Morphy, 1-35. London, New Haven: Yale University Press. 
Phillips, Sandra S., Mark Haworth-Booth and Carol Squiers. 1997. Police pictures: the photograph as evidence. San Francisco: San Francisco Museum of Modern Art, Chronicle Books.

Pinney, Christopher. 1992. Montage, doubling and the mouth of god. In Ethnographic film aesthetics and narrative traditions: proceedings from NAFA 2, eds. Peter lan Crawford and Jan K. Simonsen, 77-106. Aarhus: Intervention Press.

Pinney, Christopher. 1997. Camera Indica: the social life of Indian photographs. London: Reaktion Books.

Rajadhyaksha, Ashish. 1994. India's silent cinema: "a viewer's view". In Light of Asia: Indian silent cinema 1912-1934, eds. Suresh Chabria and Paolo Cherchi Usai, 2540. New Delhi: Wiley Eastern.

Rajadhyaksha, Ashish and Paul Willemen. 1994. Encyclopaedia of Indian cinema. London, New Delhi: British Film Institute, Oxford University Press.

Ruby, Jay. 2000. Picturing culture: explorations in film and anthropology. Chicago: University of Chicago Press.

Tarlo, Emma. 1996. Clothing matters: dress and identity in India. London: Hurst and Company.

Taylor, Lucien. 1998. "Visual anthropology is dead, long live visual anthropology". American Anthropologist, vol. 100, no. 2: 534-537.

Thomas, Nicholas. 1991. Entangled objects: exchange, material culture, and colonialism in the Pacific. Cambridge, MA, London: Harvard University Press.

Vaughan, Megan. 1991. Curing their ills: colonial power illness. Stanford: Stanford University Press.

MARCUS BANKS é Professor de Antropologia Visual na Universidade de Oxford, Reino Unido. Suas publicações mais recentes são Visual Methods in Social Research (Sage 2015, em coautoria com David Zeitlyn), e a coleção de ensaios Visual Histories of South Asia (Primus Books, 2018, coeditada com Annamaria Motrescu-Mayes). Email: marcus. banks@anthro.ox.ac.uk 